\title{
Le serpent et la souris
}

Scène vue et entendue pendant une visite au Musée Dyche

La souris Akatpatt est introduite par un gardien dans la cage du serpent Prensontemps. Elle atterrit à quatre pattes sur le sable chaud. Elle ne voit pas le serpent qui prend son temps avant de bouger pour lui signaler sa présence.

Akatpatt se croyant seule:

-"C'est un peu triste ici. Il y fait chaud. II n'y a rien à voir. Si, je vois du sable partout. Là près de moi, je vois une grosse queue... Cette

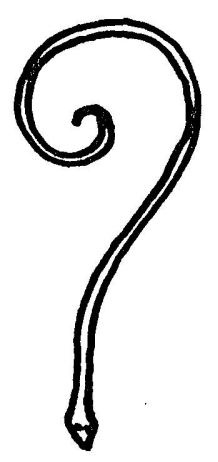
très longue queue appartient à une souris qui est certainement très grosse."

(marchant un peu pour voir)

-'Mais il n'y a pas d'autre souris ici, Ceci est seulement une queue. $C$ 'est une queue sans souris. Comme cela doit être amusant une souris sans queue. Mais que signifie.une queue toute seule. Cela ressemble à un point d'interrogation très grand pour une question."

Prensontemps, bougeant très peu la tête:

-"Que dites-vous Akatpatt. A qui parlez-vous. Est-ce à moi que vous parlez, me parlez-vous. Et... de qui parlez-vous, Parlez-vous de moi. 
Akatpatt, regardant cet étrange objet, le serpent:

-"Je me parle. Je me parle à moi seule. Mais... qui m'a posé cette question. Je me croyais toute seule.

Prensontemps, souriant:

-"C'est moi, c'est moi qui ai parlé, espèce de "Minipatt." Sachez que je ne suis pas une queue et que je ne suis pas un grand nez non plus. En effet, je suis un serpent beau et noble qui n'a pas de poils gris et laids. J'ai de belles écailles, des écailles vertes et noires. Tu es sotte (Je te dis "tu" maintenant, c'est ce que tu merites).

Akatpatt, inquiète d'avoir vexé le serpent:

-"Pardon. Mille fois pardon

(desirant se venger de son nom humiliant de "Minipatt")

-"Si tu m'appelles "minipatt" une seconde fois, moi, je t'appellerai "Queuesansnez." C'est tout.

Prensontemps, plus hypocrite que jamais:

-"Tu es impertinente, petite souris, mais je t'aime quand-même. Tu es même la souris de mes rêves. Tu es la souris sans soucis dont je rêve. J'avais 1 'air méchant tout à 1 'heure. Regarde. Maintenant, je souris. Souris-tu toi aussi."

Akatpatt, éclatant de rire:

-"Moi, je "souris" tout le temps."

Prensontemps:

-"Moi, je ris parfois, et pour cela, j'ouvre la 
bouche bien grande... comme cela."

(Il ouvre la bouche).

Akatpatt:

-"Tu as une très grande bouche."

(E1le avance un peu),

-"Eh. Tu n'as pas de grandes dents devant. Eh. Comme la langue est mince."

(Elle regarde plus près pour mieux voir)

-"Ta gorge est noire et humide comme une grotte. Oh. Une porte claque.

Il fait noir.

Je ne peux pas sortir.

Qu'est-ce qui se p...

Que s'est-il passé?

Prensontemps ressemble à une souris maintenant, une souris avec une longue queue et un gros ventre...

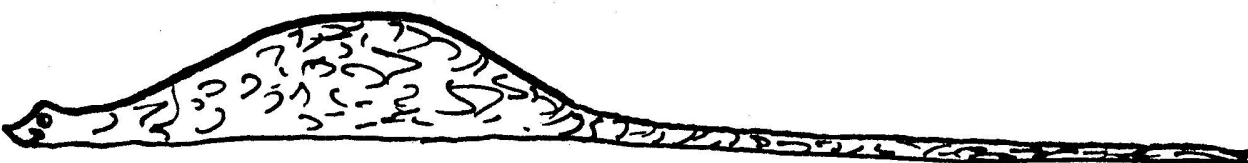

